The optical and physical properties of mica

This content has been downloaded from IOPscience. Please scroll down to see the full text. 1901 Trans. Opt. Soc. 31

(http://iopscience.iop.org/1475-4878/3/1/301)

View the table of contents for this issue, or go to the journal homepage for more

Download details:

IP Address: 129.101.79.200

This content was downloaded on 04/09/2014 at 12:32

Please note that terms and conditions apply. 


\section{THE OPTICAL AND PHYSICAL PROPERTIES OF MICA.}

Pafer by Professor Silvanus P. Thompson, F.R.S., Member. Read before the Optical Society on November 28th, 1901.

GENTLEMEN: I have chosen the subject of "The Optical and Physical Properties of Mica" for my lecture this evening, because I have found the study of the optical and physical properties of that substance exceedingly interesting, and I have found it very hard to get any information about it from books. And therefore, as it is rather an obscure but an intensely interesting branch of optics, I thought it might be worth while to put together what $I$ have learned, and to tell you about it.

In the first place, I suppose I need not do very much to emphasise the difference between mica and talc. This material (mica), which you all know, is transparent, thin, flexible, easily capable of being split into thin sheets, and is used nowadays for very many purposes, such as lamp shades, fronts of furnaces, and innumerable other services. It is also used in a variety of electrical apparatus as an insulating material. It is a material which is perfectly familiar to everybody, and yet people will persist in ealling it talc. I have in my hand here a piece of real talc, and I think you will agree that a stone more optically different from true mica would be hard to imagine. This talc is soft, splitty, fibrous more or less, and if you examine the sample, you will see that it would be of precious little use to anybody for any optical purpose. Therefore I will say nothing more about talc, but confine my remarks entirely to the subject of mica.

Mica is the generic name given to a number of minerals, all of them essentially mixed silicates-silicate of magnesia, silicate of alumina or silicate of iron, along with potash, and other chemical elements, combined in certain relations rather than in certain proportions. They all agree in having this easily laminated character, in having a certain curious crystalline structure, and though they differ considerably in their compositions, they are all very nearly of the same specific gravity. 
But they differ widely in optical properties, The names given by mineralogists to the different varieties $I$ have put upon the board in the form of a table.

\section{VARIETIES OF MICA.}

\begin{tabular}{|c|c|c|c|c|}
\hline & SP, GRAV. & $\triangle X E S$. & ANGLE. & $\begin{array}{l}\text { INDEX OF } \\
\text { REFRACTION. }\end{array}$ \\
\hline 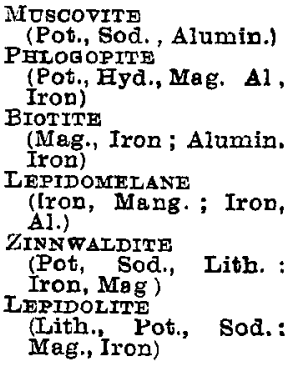 & $\begin{array}{l}2 \cdot 7 \text { to } 29 \\
272 \\
2 \cdot 7 \text { to } 31 \\
29 \text { to } 3 \cdot 1 \\
29 \\
2.8\end{array}$ & $\begin{array}{c}\text { biaxial } \\
\text { biaxial } \\
\text { uniaxial? } \\
\left\{\begin{array}{c}\text { uniaxial } \\
\text { and } \\
\text { biaxial } \\
\text { biaxial }\end{array}\right\} \\
\left\{\begin{array}{c}\text { biaxial } \\
\text { and } \\
\text { uniaxial }\end{array}\right\}\end{array}$ & $\begin{array}{c}55^{\circ} \text { to } 75^{\circ} \\
7^{\circ} \text { to } 18^{\circ} \\
0^{\circ} \text { or nearly } \\
? \\
50^{\circ} \text { to } 67^{\circ} \\
\left\{\begin{array}{c}76^{\circ} \text { to } 86^{\circ} \\
0^{\circ} \text { or nearly }\end{array}\right\}\end{array}$ & $\begin{array}{l}11.56 \text { to } 61 \\
1.562 \text { to } 1.606\end{array}$ \\
\hline
\end{tabular}

The most familiar kind, Muscovite, is that known in the middle ages as Muscovy Glass, and I have here a sample of the Siberian or Russian mica. This is the form in which it comes very often to this country from Russia, trimmed round with a sickle at the edge, and already split into fairly thin pieces, but capable of being split again and again. The natural form of it, before it has been split and dressed, is very different. Here I have a thicker slab of a natural crystal of Muscovite. You will see it has, generally, roughly speaking, a sort of six-sided appearance. It occurs in this way as rough crystals. These things are found in various parts of the earth, and are found of very different sizes. Here I have a little sample of granite containing mica, which I picked up last summer in Glen Sannox, in Scotland. Then I have another piece which is of a somewhat dirty appearance, with a contorted grain, and not at all transparent; here is another specimen which is fairly shiny, and here is a piece of micaceous schist which is really much more like the tale I showed you just now. Here I have a sample of mica which looks very much like snow, or powdered silver. I believe that has been heated in order to get it into those white silver flakes. And here is a material found native in Germany-I am not sure if this particular specimen has been artificially treated-but it is a golden mica which is flaked up in the same way and called by the Germans "Katzen-gold," or Cat-gold. Whether 
you find it in small flakes mixed with other constituents like that Scotch specimen, whether in irregular lumps, in small erystals or large, it has the same peculiarity of being readily cleaved, in one particular direction, into thin sheets. It has been found in certain places of enormous size. In Virginia there was once found a crystal which weighed about a ton: it was nearly three feet across and more than a foot thick, but it could be cleaved into large sheets. Here I have a sample not of that particular piece, but a portion of one of those six-sided crystals, but clipped across at one side. It is nearly 20 ins, across. There is a slice, not very transparent, of a brown colour, and there are several others on the table here, intended simply to exhibit the crystalline form. The one I have now in my hand is a sample of Australian mica, not Muscovite, but a specimen of the last variety shown on my list, namely, Lepidolite, of a purple or peachy colour.

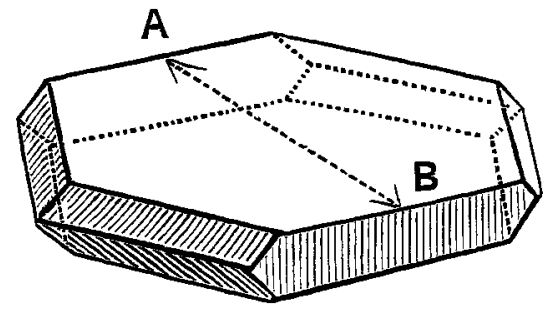

FIG. 1.-MODEI, OF NATURAL CKYSTAL OF MICA.

Here is another sample of this same Australian Lepidolite, and here is a bit of brown Phloyopite. I have here samples of most of the different kinds of mica. Here for instance is a block of the kind known as Biotite, which is very flexible, but very splitty. It breaks up easily, and is not a very useful variety. Then there is a small specimen here of the very black kind known as Lepidomelane. It is black because it contains iron and manganese-principally iron, both in the ferrons and the ferric state. It is an exceedingly black sort, and is usually found in thin flakes. Of Zinnucaldite I have no sample; it is rather rare, but it is only interesting because it differs somewhat, externally, from the others. I have shown you the Lepidolite because it contains a large amount of the element lithia. All these, with the exception of Zinnwaldite, may be said to have a certain primitive form, the same form as this block of wood here (fig. 1) which, as you see, is a sort of six-sided form, but not exactly the same on all the six sides, two of them are straight, and the other four generally are more or less sloping. 
We find, as a matter of fact, that the crystal has certain properties in the direction across from one straight side to the other, in which direction, marked $A B$ in fig. 1, its properties differ from the properties in other directions. This you will learn presently when I say more about them.

Mica does not belong to the hexagonal system (fig. 4) of crystals, however. It was for a long time thought to belong to the rhombic system, that is to say, the system of which the primitive form is somewhat of the shape of a match box, with three different axes in three different directions at right angles to one another. But it is now known that it does not belong to the rhombic system (fig. 2) - it really belongs to the form called monoclinic, wherein two of the axes are at right angles to one another, and the third is oblique to the other two; as though the shape had been raked or tilted over (fig. 3). Now I suppose you

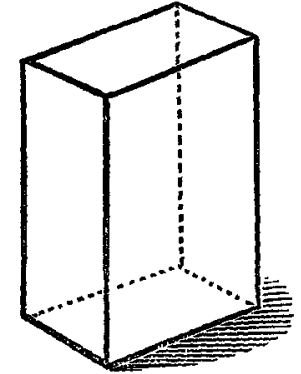

FIG. 2.-RIGHT RHOMBIC SYSTEM.

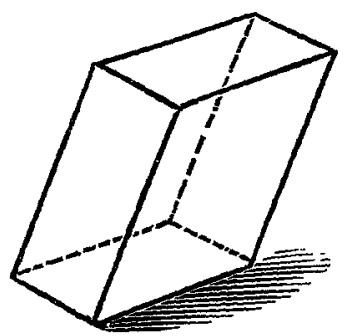

FIG. 3.-MONOCLINIC SYSTEM.

will say this hexagon does not look very much like a square block raked over on one side. No, perhaps not, but then remember the external form of the crystal is determined very often by its tendency to split. Take, for example, the common double-refracting Iceland spar. The crystalline form to which we should refer it as a system is the six-sided system, having a principal axis around which the other axes are grouped symmetrically. But, as a matter of fact, the natural planes of cleavage, which are three in number, are all three inclined to the axis of the hexagonal system. Consequently when you have split this up it splits up into rhombohedrons. It imitates, in one sense, the monoclinic form, but nevertheless it is, optically, a crystal having but one axis, and belonging truly to the hexagonal system. So, in the same way, this crystal mica, which belongs to the monoclinic system, imitates the hexagonal system by its cleavages. It has 
various cleavages, but one particular plane, which is more prouounced than the other-the plane parallel to which it cleaves-is considered as its base, and we have, practically, to consider it only with respect to this plane of cleavage. Now the monoclinic and rhombic systems, both of them, as well as the hexagonal, are systems which, because they have these inequalities in their axes, are not symmetrical around and along their principal axes, as the other systems, the cubical, the tetragonal and the hexagonal systems, are. So not being symmetrical around one axis, the consequence is that the rhombic, the monoclinic, and the triclinic systems have two oblique directions through the crystal which are axes of maximum elasticity, with axes of minimum elasticity at right angles; and therefore they are optically biaxial. They will

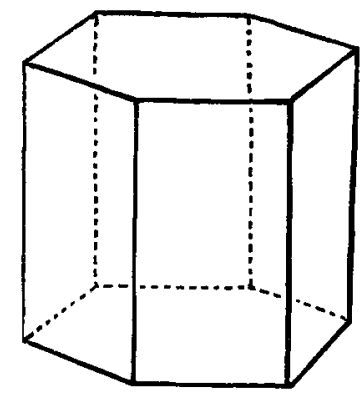

FIG. 4.- HEXAGONAL sYSTEMr.

show in polarised light symmetrical patterns around the two axes instead of giving simple rings and crosses around one axis. Herein lies the easiest method of discriminating the different kinds of mica, as to whether they are biaxial or uniaxial, and if biaxial how wide apart the axes are from one another. I will come to that, perhaps, presently. Once more I will draw your attention to the general sixsidedness of the outline of this crystal. The rest of the samples in this group are intended to show you how this crystalline form reappears in certain of the natural angles. Here is a piece for example -a piece with the natural six sides, and I think cut a little out of true in one case. Here is another piece which is, in fact, two put together naturally as a twin crystal. One of the difficulties in handling mica is that it is so apt to split, and, therefore, I must ask you much as you would desire to do so, to be very careful to try and not on any account split my crystals for me. Some of the very finest speoi- 
mens are not mine, they are kindly lent to me for this occasion by Messrs. Wiggins and Sons, the well-known mica merchants, and I should be very sorry if any accident happened to these specimens.

Passing away from the general structure to the question of colours, you will see that mica has many different tints. Some of these specimens are red, some brown, some green, some grey. Here is a sample of a very good quality of Mnscovite, and here is a piece of comparatively rougher stuff. I will refer to that one again presently. These samples are to illustrate the differences of colour. Here is a very fine piece of greenish grey, nearly uniform in colour, and here is a piece nearly black, so dark that you cannot see through it. Here again is a piece which looks almost black on the surface-it is a kind of greenish bronze. Here is a very beautiful piece of grey, fairly transparent, and if it were thinner it would be quite transparent. Here is a piece of that Lepidolite from Australia, and here is a sample from India-I do not know whether from Bengal or Ceylon-of a kind called Port Wine Mica. It is of an exceedingly dark red colour like a ruby glass. The specimens of the next group are four in number; and they are to illustrate what so very often happens in the case of mica, namely, that included between the lamine of the mica there are other substances which we call "inclusions." Here, for example, is a very beautiful piece illustrating inclusion: the dark streaks probably consisting of thin films of oxide of iron, some black, some brown, included in between the laminx. Here is a fine piebald specimen-a rewarkable piebald specimen-with streaks of brown and black running in all directions, and when you look at it on the surface it shows in certain directions beautiful rainbow colours due to the interference of light at its thin plates. I do not propose to send round these "inclusions" as they might get injured. Here is a great rarity, a piece of mica, which includes not only a number of black specks, which I take to be bits of tourmaline or oxides of iron, but certain red speclss which I believe to be garnets interspersed in thin flakes among the laminæ of the mica.

Then another peculiarity which happens is this: that as with amethysts, as even with diamonds sometimes, and with a great many crystals, you frequently find two crystals growing into one another, and forming twins; and they are not always of the same tint or same description, but have their axes in different directions. I have an arc lamp here to enable me to get a more brilliant light, and $I$ will turn that on, and put a ground glass in front of it, so that you will be able 
to see clearly the objects which I am about to show you. You can see these things very well if they are held in front of this light, because they have a transparency of their own. Here is the mottled piece, here is the piece with garnets enclosed, and here is the piece with tourmaline included in the centre. Now for the twins. They are, perhaps, not so easy to observe. This crystal, if you notice, appears to be made of two parts, one light and one dark. It really is two crystals which have grown naturally together, and have been built up side by side. An examination with polarised light shows that the axes of the crystals are in different directions. Here is another curious twin, where a corner of one crystal has penetrated into another one, evidenced by a slight change of tint. Here is another one with an obtuse corner of one crystal running into another, and another with an acute corner running into another, visible by reason of a slight difference of the brown tint; and here is a very remarkable one-you may not notice anything from that distance, but this really consists of three crystals, one piece at each end, and another in the middle, as is evident from the colour. If I turn it slightly round you will see that the part which was orange goes red, and the part which was red goes orange. If we had daylight you would see it better, but, unfortunately, daylight is not at our command. You get these singular changes of colour in viewing it from different angles. Now that proves that they are differont crystals twinned together.

Then there is the curious and well-known phenomenon of asterismthat is to say, the production of stars. To show you the asterism I must have a light of a different kind, instead of having a diffused light I must have a point; and for that purpose I will simply take this little glow lamp and show you the lamp behind some of these pieces of mica, and you will notice at once there are six rays round that point of light, and they revolve as the sheet of mica is turned. Then here is a piece which has eight rays, that is one which has the six with an additional two. I am afraid this cannot be seen very well from a distance, but if you put it to your eyes you can see that one part of the sheet is pale and the other dark, through the light part you see six rays, and through the dark part you can see the other two rays, making eight in all. Here is a piece of 12-rayed mica-a star with 12 arms-and here is a piece which is very uncommon, with six principal rays and other six in between, maliing it 12-rayed, but with rays not all equal. Here is another piece of 12-rayed mica, and here is a piece of Indian mica, dark red, which shows only two rays which are very faint. I 
doubt whether you will see them because it needs a still more brilliant light than we have bere; but if you were sufficiently near you would be able to see two rays, one each side, right and left. Well, you see we have two-rayed, six-rayed, eight-rayed, and 12-rayed mica. These asterisms, no doubt, depend upon minute structures, minute crystals which follow the general lines of crystallisation.

Now let us go back to my model (fig. 1), so to speak, my primitive crystal. If you were to take this piece of six-rayed mica, the six rays would be in this position; one pair will go at right angles across the line $A B$ between those two sides which $I$ have referred to as being different from the others; the two other pairs will cross the line at angles of 60 degrees, going angularly towards the corners. The phenomenon of asterism has long been known; you know there are certain star-sapphires which will show the same thing, and also certain star-rubies which show the same general phenomenon of six rays. Now there was discovered about 20 or 30 years ago by a certain German professor a very remarkable thing-namely, this. Suppose you take a piece of mica, which must be one you are prepared to sacrifice, and put it down on a fairly flat piece of wood and hit it with a round-ended punch, there will result what he called a "Schlagfigur," -a figure which results from a blow. The kind of pattern you get as the result of hitting mica in that way is different in different kinds of mica. It has something to do with the internal structure of mica. Here I have a very beautiful Schlagfigur, in a sample lent me by $\mathbf{M r}$. Wiggins. I do not know how it occurred, but the sheet has been hit somehow or another at one point, and there has started a streak in the form of a star. These figures are generally less than a quarter of an inch across, and have to be looked at through a magnifying glass. This one is unusually large. Now if you take either Muscovite or Phlogopite or any kind except Biotite or Lepidolite, and hit it, you get a six-sided star which follows exactly the same lines across the crystal as the star which you see. One pair of arms of the six-sided star, see fig. 9, will lie across between the two straight sides at right angles to the line $A B$ in fig. 1 and fig. 9.

I have not yet got to the end of describing the optical properties, in fact, I have hardly yet begun with the optical properties. I have mentioned quite briefly that some mica is transparent, and other kinds comparatively opaque. That opacity is almost always due to the presence of these additional minerals-either iron, or chromium sometimes, or manganese. I would like now to dispose of the questions 
involving the chemistry of them, and so I will first show you an experiment, which was shown to me two days ago by Mr. Wiggins. Here is some Lepidolite from Australia. I do not know whether it is all equally good for the purpose, but suppose we take a piece and split off a little bit. I have two samples which are not equally good, but they are supposed to have come from the same place. This mineral contains soda and lithia; when it is heated in the flame of a Bansen burner, you will see the yellow tinge which you get with saltsodium-(for micas all contain sodium more or less) - but if it contains enough lithia you will also see now and then a strikingly beatiful crimson colouration given to the flame; this colouration being characteristic of the metal lithium. If you had a spectroscope to examine the flame you would see the characteristic bright red line of lithium. You see when 1 hold it in the flame it actually melts. Having got it melted at the top of the flame I bring it down towards the bottom and you observe that fine crimson colour. There is still another thing I want to show you about this same Lepidolite, and for that purpose I must have the room put into darkness by turning down the lights. If you take a piece of mica and split it in the dark you can sometimes see flashes of light emitted, and I am going to split off a bit of this kind of mica in order to show you. You see how it flashes. Now I will take a bit when it is split off, and bend it abruptly in the dark, and when I do that you see it flashing internally. No doubt that is an electrical discharge inside, and the peculiar crimson colouring is, I believe, due to the same circumstance as I have already pointed out-that it contains lithia.

Micas differ greatly from one another in transparency, as you hare seen. The transparency of the material depends obviously upon the greater or less amount of absorption of the light by these dark substances that it contains. It very soon becomes opaque if you plle it up thick. If you take a great thick piece like that which I have here and try to see through it, you cannot. Now it is not generally known-I certainly did not kuow it myself until a few days agothat mica, though it is, when thick, opaque enough, yet nerertheless is extraordinarily transparent in the edge direction. Now you wonld naturally think that a material that was like these ordinary specimens, opaque when in slabs 1 in. thick, ought certainly to be quite as opaque if it was an inch thick in the edgewise direction. Bat Mr. Wiggins showed me an exceedingly beautiful thing the other day, which he has very kindly lent me in order that I may show it to you. Here 
is a column up the centre of which runs an iron rod. Upon that rod are threaded a large number of washers of mica of different kinds, pressed down together and then turned in a lathe and polished. I hare the means here of lighting up this column from behind, and when you have the light behind this column of mica you will see that it looks almost like a bottle containing oil. Some of the bands are exceedingly black, but some are of amber tint, and some very light. You are looking through 2 ins. of thickness, and yet you see how wonderfully clear they are. In the bottom of the column there are a number of green pieces of mica, and a number of red ones. I do not know what the particular varieties are in that column, from top to bottom, but it is very clear that there are many different varieties. I hardly need say anything more about it.

The " manufactured mica" that is now being used so largely for electrical insulating consists of scraps of mica which are waste for other purposes, but which are stuck together with shellac and heated under pressure in a stove, so as to be very hard. But this manufactured mica, or micanite, is quite uninteresting from the optical point, of view. I would like to show you one result of handling mica artificially. Take a piece of ordinary Muscovite and put it into a furnace and heat it. It comes out (showing some burnt mica) looking almost like silver on the surface, very easily flaked off, looking, in fact, almost like silver leaf. Here are the two pieces of the same mica baked and unbaked, that you may see the contrast between them.

Now let me go from this to the genuine optical study of mica. You are all familiar, I believe. with the tourmaline forceps which are used in examining pebble lenses to distinguish them from glass lenses. You know that you have to adjust these two pieces of tourmaline across one another, so as to have the light cut off as much as possible; and then if you wanted to examine your piece of pebble you would put it in between the two tourmalines and look not at a point of light such as this lamp, but at a white cloud or a white surface. Now if you examine any one of those pieces of mica that are clear and transparent by putting it between the tourmaline forceps, you get some very remarkable results. Unfortunately, however, I cannot provide you all with tourmaline forceps, and therefore $I$ must resort to another mode of showing you what is to be seen there. I will adopt the polarising microscope as adapted to the optical lantern; and I will throw upon the screen a number of examples of crystals viewed by convergent polarised light, that is as they would be viewed by eye in these tourmaline forceps. 
Briefly, to describe the arrangement, I have an arc lamp in the lantern, with the usual condenser lenses, then a large polarising Nicol prism, and then a system of lenses which will bring the light down highly convergent upon the crystal ; then a certain system of lenses to receive that light and render it again nearly parallel, and last of all another Nicol prism to serve as an analyser. The Nicol prisms serve on the large scale as the tourmalines of the forceps do on the small scale. When the Nicols are crossed I have the "dark" field, and when they are parallel the "light" field. And to begin with something familiar I will take a piece of ordinary cale spar, which is a uniaxial crystal, and when examined in this way gives you the familiar black cross and a system of coloured rings (fig. 5), of the same sort as you observe in a

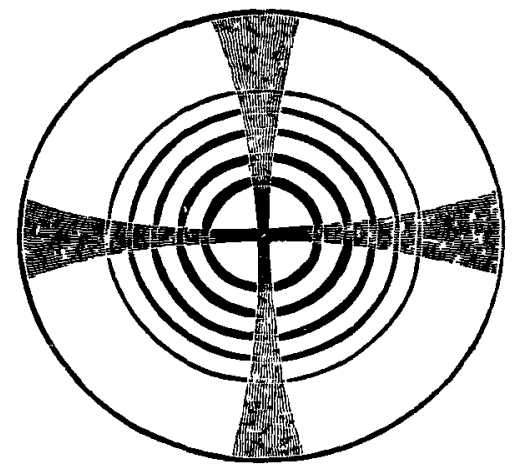

FIG 5.-RINGS AND CROSS IN UNIAXIAL CRYSTAI.

piece of pebble or quartz, with which you are possibly more familiar than with Iceland spar. You will notice that in the case of the quartz the black cross does not go across the middle. In the case of quartz we get a central portion of it which changes colour if one of the prisms be rotated. The piece I bave showed you first was a piece of Iceland spar. Now I will take a thinner piece, and you will see that that thinner piece gives me a somewhat larger pattern. I still get the cross but the rings are somewhat larger. Now I take a still thinner piece and you observe that the thinner the piece the larger the ring pattern for one and the same substance. This is Iceland spar and it is a uniaxial crystal, and must be cut so as to be able to look along the axis in order to obtain those rings and that cross. If the piece is not cut quite across the axis, exactly across, the cross will not be in the midale of the field. If you notice in the one case it is rather lower 
down in the middle, and as I turn the piece round the cross shifts. That shows that it is not cut quite straight. If you were looking down the axis, the pattern would be absolutely centered in the middle. Now to make us familiar with this let us take two other crystals known to be uniaxial. Let us take a little piece of ruby. It gives you the same thing but on a somewhat larger scale, the substance being less strongly double-refracting. Ruby is less powerfully double-refracting than the calc spar or quartz, and consequently, for an equal thickness, the rings are larger. Here is a piece of jacinth, and with that you see the same sort of thing. Here is a piece of pale emerald, and I wish you to compare that with the ruby. Here is a crystal called brucite, and in that you will observe the same sort of thing, only the rings are on a larger scale. Here is a crystal coming from the Ural Mountains, called a phenakite--practically a white emerald-a gem much rarer than the diamond, but much less worth, and which is frequently palmed off on unwary purchasers as a diamond. It is a white crystal, and it, unlike the diamond, also shows the same system of rings and crosses.

But now if we pass from these uniaxial crystals to those which belong to those other crystalline systems, of which I have spoken, which have axes in different directions-axes of maximum and minimum elasticity - see what the result is. I take a piece of aragonite, and as a result of putting it into the proper position it gives me, as before, a black cross in the dark field, but the black cross has not got a system of rings round the middle of it; in fact you see there are two centres, or "eyes," and if I turn it round a bit I get those two "eyes" separated, and if $I$ go on turning it then the cross forms again. Figs. 6 and 7 show the general appearance. There is really a system of rings round both those "eyes." On continuing to revolve the crystal so that the "eyes" return into the horizontal line, we come back to the black cross again. Each " eye" surrounds an optical axis. Now that is a typical biaxial crystal; but typical with the possibility of there being many great variations. Let us take another biaxial-a piece of common saltpetre. There are the two axes again, you see, but they are much nearer together. If we turn the crystal round, the black cross splits up into these two curved brushes (fig. 7), one passing through each eye. In fact the black cross has parted into two curved portions which re-unite when the crystal has been turned through a right angle. Now I take another biaxial crystal, namely, a piece of baryta. Again you have a black cross, the upright bar of which is a good deal enlarged, and hazy, but having a very much thinner cross 
bar right and left. But see how large the "eyes" are in this case, and what wonderful colours we have arranged in rings. When I turn the specimen round the pattern opens out into those two "houppes," or brushes, and with further rotation reforms, breaks up again, and

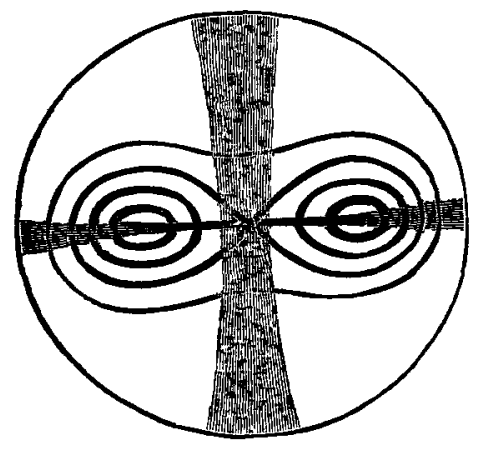

Fig. 6.-Cross and CURVES IN BIAXIAL CRYSTal.

again reforms. You can see all that by personal observation with the tourmaline forceps. If we take any of these biaxial crystals-take a piece of topaz, for instance-it gives the same thing; but in the case of topaz the axes are wider apart. It is a biaxial crystal, with a wider

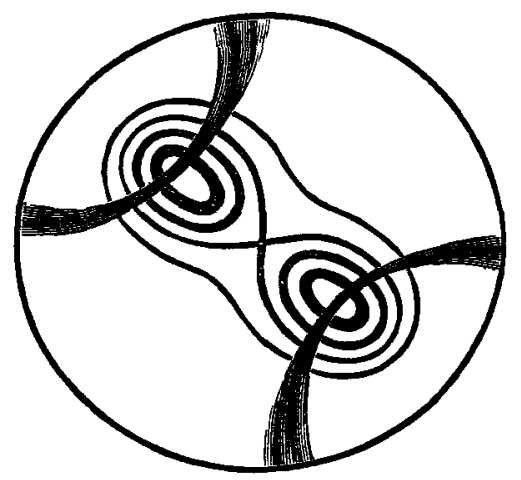

FIG. 7.-CURVES AND BRUSHES IN BIAXIAL CRYSTAI SET OBLIQUELY. angle between the axes. I turn the crystal round and the pattern opens out and reforms with the black cross which breaks up and reforms again. Here is a crystal of sugar, cut in a particular way across the axes. There is not so much colour, but there are the two 
"eyes" characteristic of the biaxial crystal, the two axes being very wide apart. And here is another piece of crystal. This is carbonate of lead. Now this differs completely in detail from the sugar. But both, the sugar and the topaz, have their two axes very wide apart. Now we come to crystals which have the axes very near together, with only a comparatively small angle of $4^{\circ}$ or $5^{\circ}$ between them; and in this case the two systems of rings melt into one another-you have the two eyes with the two systems of rings round them, but the rings blend into one another and give us a system of ovals (fig. 8). So that the narrow-angled biaxial crystal differs in detail on the one hand from the uniaxial crystal, or on the other from the wide-angled biaxial. Here is a piece of crystal called sanidin, it is of the same biaxial species, but with a moderate angle. You see a system of rings round each axis, and you also see some of the ovals

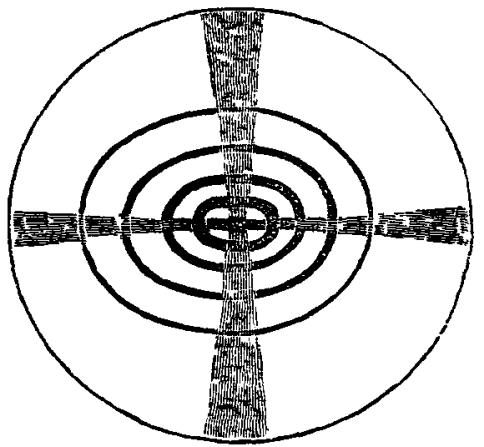

Fig. 8.- CURYES AND CROSS IN BIAXIAL CRYSTAL OF NARROW ANGLE.

embracing both the axes. I take another piece of sanidin. There is the black cross with the two axes, but it is, I suppose, quite obvious that the angle between is small, and we have a system of ovals which embraces both axes. Now I talke another crystal, a piece of axinite, in which crystal the angles are so wide apart-nearly $90^{\circ}$ - that we can only see one axis at a time; but we can see it is not a uniaxial system, because the rings have got a black streak and not a black cross coming through them. We have the "houppes," but not the "cross." The cross is in these biaxial crystals broken up into two parts-one arm goes through one eye, and the other goes through the other eye ; and the second "eye" is not in the present instance within the 
field of view. Here is a piee of clear talc (notmica) which is obviously a biaxial, though it looks very like a uniaxial. There is a cross, but the rings are not circular, they are oval, and when we turn the crystal a little bit, the cross splits at the centre, showing that it is clearly a biaxial crystal.

Well, then, we have now learned to discriminate between uniaxial and biaxial crystals. So far, I have not been using mica at all in these experiments. Now let us see what mica will do. Here is a little piece of mica from India, and at once you see it is obviously a biaxial crystal, giving the form characteristic of a fairly wide-angled biaxial crystal, with a great dispersion of colour; and that last feature is characteristic of all the micas. The next piece-I do not know the place of its origin-is a piece of green mica, and again it is a biaxial. But it does not give us so black a cross. Now I take another piece of biaxial mica of a different thickness-it is a somewhat thinner piece and therefore the pattern is larger. The thicker the piece the more concentrated the rings around the two centres of the pattern. Here is another piece of biaxial mica, but lools how different it is, with a comparatively small angle, so that we get the ovals instead of either circles or even a regular pair of "eyes." Here is a piece of substance called " uniaxial mica," but it does not give very perfect rings. Turn the crystal round and we see them wobble a little bit, showing that they are really ovals; it is just opening into a biaxial, though on the first appearance it seemed to be purely a uniaxial crystal. I suspect all the so-called uniaxial micas to be really biaxial micas with a very small angle between their axes.

What will happen if you take two pieces of mica and cross them one over the over? I will take two pieces of mica, just ordinary stuff. There is nothing special about the sample; it is just ordinary good Muscovite, rather thin, and therefore you see the pattern to be very large. Take another one, the same sort of thing, split oft the same piece. It shows a similar pattern. Sow what will happen if I put the two pieces into the polarising apparatus so that they lie across one another? If I set one one way at about $45^{\circ}$ and the other at $45^{\circ}$ the other way, I get four "eyes" instead of two, and when I rotate the combination I have an oblique cross with the "ejes" at the corners, instead of their being situated on the arms of the cross. These are the curious effects produced by crossing two pieces of mica over each other. I hare a little slide here in which two pieces of topaz are similarly crossed over each other. There you see 
the black cross with the eyes at the corners, or, in another position, the black cross with the four "eyes," right and left, up and down. The specimen shows exactly the same beautiful pattern in the tourmaline forceps I have here two other samples of mica, which I made from some of these sheets on the table. Here is a piece trom Ceylon, of very easily bent mica, which is found to be very nearly uniaxial. I thought it was so at first, but, on examination, it is certainly not. In the present position you see the rings are oval. It is not really a monoaxial crystal. Lastly, here is a piece of that pink-coloured Lepidolite, which is supposed to be monoaxial; but you see again it is not a true monoaxial mica. It possesses a slight tendency to diverge into two axes. So much for the properties of mica when examined by the polarising microscope, or by the tourmaline forceps. To use these tourmaline forceps you want a good cloud or a good white surface, or a lamp with a good opal shade over it. Inserting the crystal, at once you see the black cross, or the houppes. If there is any doubt about the crystal turn it round and see whether the cross splits up into two houppes or not. Now see how this enables you to discriminate between the different kinds of mica. With Muscovite (biaxial), the angles are never less than $55^{\circ}$ and never greater than $75^{\circ}$, the angles being measured in the air. Thus you are able to discriminate between different kinds of Muscovite which vary with the amount of potash, or soda, or alumina, in them. Phlogopite, as the table (p.2) shows, is biaxial. It varies between $7^{\circ}$ and $18^{\circ}$. It has water and hydrogen in it, and potash, iron, or magnesia, instead of soda, and that is what makes it dark. With regard to Biotite I do not believe it to be uniaxial; the angle is very nearly $0^{\circ}$, but it may be $1^{\circ}$, or $2^{\circ}$, or $3^{\circ}$, or $4^{\circ}$, or anything up to $6^{\circ}$. Lepidomelane is so black that we do not know anything about its internal structure. Zinnwaldite is a biaxial of $60^{\circ}$ or $70^{\circ}$ according to the amounts of soda, potash, and so on, in it. With regard to Lepidolite, you will find in all the books a statement that Lepidolite is biaxial, with axes from $76^{\circ}$ to $86^{\circ}$, or even nearly up to $90^{\circ}$. Well, I have been examining these samples of Australian Lepidolite. There are certain samples you cannot examine because they are utterly untransparent. Here is a sample-it looks simply a fine grained micaceous rock. But these clear pieces of Lepidolite which I have been able to examine are all narrow-angled biaxial, almost uniaxial. I have not come across one that could be described as having a wide angle of $76^{\circ}$ or $86^{\circ}$. The position of the axes is related to the 
crystalline structure: for the line joining the two "eyes" is, in all cases, found to lie parallel to the line murked $A B$ in my model, fig. 1 ., as is also indicated diagrammatically in fig. 9.

Now there is another optical phenomenon of mica that is not generally known. I have known it for a good many years; but when I became aware of it, or whether I found it out myself or was told it, $I$ do not know. At any rate $I$ find it has been known for many years to Mr. Wiggins also, and it is this. Take one of those good biaxial micas of rather dark tint and examine it with the tourmaline forceps or with the polarising microscope. You observe the two axes with a

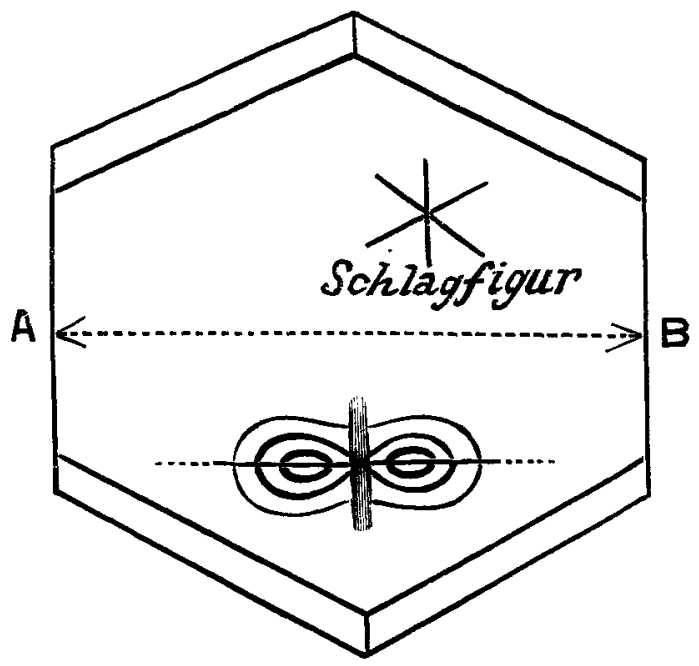

FIG. 9.-RELATIVE POSITION OF OPTICAL AXES IN CRYSTAL OF MITCA.

considerable angle between the two. Or take a narrow-angled mica. This is a piece of narrower angle - not so wide an angle as $75^{\circ}$, but more like $20^{\circ}$ or $18^{\circ}$. Well, now, there are those two eyes, but you only see those "rings" and "houppes," of course, by examining it in the polariscope. Take away the polarised light and use ordinary light; and what do you see? I remove both the Nicol prisms from my apparatus, but leave the slice of mica between the lenses. I now am using simply a magic lantern and lenses, and nothing more; and I am sending highly convergent light through the mica. Under these circumstances you will see what there is to be seen. It is exactly as though after examining the mica through the tourmaline forceps you should remove the forceps and simply put the mica close to the eye. 
You see those brushes, those houppes, as we call them. The rings have disappeared, but the houppes are visible against a bright background. Those houppes are where the "eyes" would be, if the light were polarised by tourmalines or Nicol prisms. But you sce they are visible without any polarising apparatus at all. All you want is a good white cloud or luminous background. Put the mica close to your eye and tilt it about and look at a good white cloud, and you will observe the very thing that I have shown you on the screen (fig. 10). Now I will show you the finest piece of mica I have ever seen, not the largest, but the finest piece for the particular purpose in question, namely, for showing these houppes. It is a dark piece, you see, with a slight "twin" in it, but it is a wonderfully even piece and of considerable value in money. I place it in front of this lamp shaded

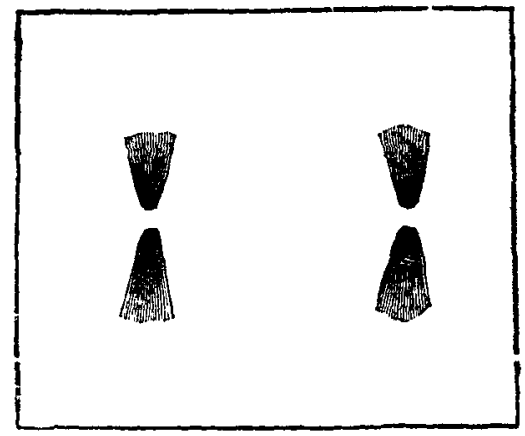

FIG. 10.- HOUPPES SEEN IN BIAXIAI MICA.

with an opal globe. And now, if you are anywhere near, and look in with one eye, you will be able to see those same houppes. You can see it is biaxial for there are two sets of houppes. Now, looking steadily in one direction, you can absolutely measure the angle in between the axes, by tinding out how many degrees you have got to tilt the slice in order to shift one or other of the pairs of houppes into the line of sight. This phenomenon of mica does not appear to le nentioned in any book on optics: but $I$ have found that it was known to Brewster, who mentions it in one of his researehes. I have linown it for some time-I do not know how long. I has a piece of it here, with my handwriting on it, of some years igu. "Indian mica shows the houppes." I knew it, and Mr. Wiggins linew it also. All those pieces that clange colour when held in dnew ut drections show the same thing. You will see those houppes 
quite plainly. There are other minerals, epidute, axinite, and andalusite, which with some rariations show these houppes, but there is no substance which is so ensily accessible to show them as mica.

Now one result of mica being so delightfully easily split into thin films is this. You can show in the thin films of mica some of the most extraordinary and beautiful effects of physical optics, including those of plane polarised light. I have several combinations here-several combinations made artificially by building up thin mica crossed at regular angles. The first man who did this was Norremberg, and Reusch followed Norremberg. I will show you some of Norremberg's combinations. Take a number of pieces of mica-4, 6, 8, 10 or 12-all cut from the same piece so as to be of equal thiclsness, and place them on the top of one another, but set with their axes in different directions. First lay one down, then let the next one be turned round through a right angle, the next through two right angles, and so on. If you thus build up the films in regular order you get some very singular patterns. The first example looks, I suppose, very much like two simple pieces crossed. Now the next one shows four that have been crossed in that way, and by so crossing four the pattern is somewhat changed, you see. Vre are finding that the effect of "eyes" is crushed out at the corners while the combination is developing a system of rings in the middle. Take a larger number of films and cross them, and we obtain, at the centre, more rings, rather square in their shape, crossed by the black cross; but the four eyes are being still further crushed crushed out of existence into the extreme edge. Take a still larger number of films and cross them as described. The eyes disappear altogether, and, instead, you have a system of rings slightly squared at the intermediate corners, not quite truly circular, but constitutings a fair imitation in certain positions of uniaxial crystals, though mado by building up biaxial crystals across one another, symmetrically round the centre. Then here are some of Reusch's combinations which are equally curious. Look at that one. See how it changes as I move it round, here in the dark field and here in the light field. And here is another one of still greater complexity, made by crossing 12 micas. I tried myself very hard to produce-I mean opticallyan artificial quartz. I took 24 micas all of equal thickness, and crossed them at regular angles of $60^{\circ}, 120^{\circ}, 180^{\circ}$, and so on, and piled up all the 24 round and round in a kind of spiral one over the 
other, by which I hoped to imitate the optical behaviour of an axiscut slice of quartz crystal. That is the nearest imitation 1 could get (showing on the screen). I obtain rings, but no black cross. The centre behaves like the centre of an axis-cut quartz, and changes colour, as you see, from red to green, as the analyser is revolved. It possesses the rotatory property of the quartz, although, of course, there is not a particle of quartz in it.

Now much more might be said of interest about these optical properties of mica. I have purposely left out one whole chapter about them-namely, such as you will find in Treatises of Optics, specially in that excellent book by Mr. Lewis Wright, on "Light," wherein he describes the use of thin films of mica in a parallel polarised light for making pretty patterns. Lest you should think I have quite forgotten that there was such a thing, allow me to conclude my demonstrations by simply showing you one or two of these things. Similar slides are to be had of Newton and Company, or of Harvey and Peak, or of many other Opticians who go in for apparatus for experiments on polarised light. Here is a set of pieces of mica of the thickness known as "quarter-wave." They are arranged as 12 sectors. If I take another one which is cut in the form of a ring I get, you will observe, that curious change of colour from light to dark. Or if I take four quadrants of mica, all of the same thickness, but with their axes alternated, and put on this ring of mica over them, I get again that curious interchange of colours. These are all old things. Here is a set of patterns of mica of different thicknesses. If you look at those through parallel polarised light, but not convergent, we get no rings and no black crosses. We get flat tints depending simply on the thickness of the mica film. Here is a pattern sf stripes made of thin bits of mica. If I super-impose upon that a second one like unto it, but slightly displaced, we get a still more complex pattern, which gives us very many changes of colour as it is turned round. I might show you scores of these beautiful objects. But, as these are described in every book on polarised light, I forbear.

In conclusion, I would claim that the substance mica is well worthy of study, both from the mineralogical, the chemical, the crystalline, and the optical point of view. There is a great deal to be learned from it, and I trust you will join with me in thanking Mr. Wiggins, without whom I could not possibly have presented to you so many different specimens as I have been able to do this erening. (Loud applause.) 